\title{
Preparation, characterization and in vitro osteoblast growth of waste-derived biomaterials
}

\author{
Eduardo Saez Rojo, ${ }^{a}$ Milagros Ramos, ${ }^{\mathrm{b}}$ Malcolm Yates, ${ }^{\mathrm{c}} \mathrm{M}^{\mathrm{a}}$ Angeles Martin-Luengo, ${ }^{\text {*a }}$ \\ Ana Maria Martínez Serrano, ${ }^{b}$ Ana Civantos, ${ }^{d}$ Jose Luis López-Lacomba, ${ }^{d}$ \\ Gwendolen Reilly, ${ }^{e}$ Chris Vervaet, ${ }^{f}$ Jaume Lluis Tarterra, ${ }^{9}$ Benet Fité Luis $^{\mathrm{g}}$ \\ and Lorena Vega Argomaniz ${ }^{c}$
}

Received 11th December 2013 Accepted 20th January 2014

DOI: $10.1039 / c 3 r a 47534 d$

www.rsc.org/advances
Renewable raw biocompatible materials can be prepared from beer production waste, that due to their nature contain the main chemical components present in bone (phosphorous, silicon, magnesium and calcium). Their characteristics can be tailored for use as replacement candidates in osteoporotic treatments, coatings for prostheses, bone grafts and odontoestomatologi implants, for example, with greater cost effectiveness than conventional scaffolds and eliminating the use of non-renewable raw materials or toxic substances in their preparation.

\section{Introduction}

More than 50 million people suffered from osteoporosis in 2010 , and by 2020 due to the increasing age of the population this number is expected to rise to 60 million. Bone tissue engineering is one of the most promising approaches to be used as an alternative to conventional autogenic or allogenic surgical techniques for bone tissue repair. ${ }^{1}$

The use of synthetic materials as bone substitutes has become a possible therapy for the treatment of skeletal defects. Scaffold-based tissue engineering strategies involve the use of biocompatible and biodegradable porous materials that serve as structural templates to guide the growth development of new bone tissue supporting cell-cell interactions and extracellular matrix formation. ${ }^{2}$

Optimal scaffolds have been designed to provide mechanical stability while supporting cell colonization, migration, growth and differentiation of bone-forming cells. ${ }^{3}$ An important step in the development of scaffolds for tissue engineering is to evaluate the biocompatibility of the materials used. Due to their similarity to the chemical composition of bone, calcium phosphates can be used to regenerate osteoporotic bone as coatings that improve orthopedic implants, and for odontostomatologic

${ }^{a}$ Instituto de Ciencia de Materiales (ICMM) CSIC, Campus UAM, Cantoblanco, 28049 Madrid, Spain. E-mail: mluengo@icmm.csic.es

${ }^{b}$ Centro de Tecnología Biomédica (CTB), UPM, Madrid, Spain

'Instituto de Catálisis y Petroleoquímica (ICP) CSIC, Madrid, Spain

${ }^{d}$ Tissue Engineering Group, Institute of Biofunctional Studies, Complutense University of Madrid (UCM), Pharmacy, Madrid, Spain

${ }^{e}$ University of Sheffield - Engineering Materials, Sheffield, UK

${ }^{f}$ Laboratory of Pharmaceutical Technology UB, Ghent, Belgium

${ }^{g}$ San Miguel, Fábricas de Cerveza y Malta, S.A., Lleida, Spain applications, where their particle and crystal sizes are important parameters to be controlled to optimise these processes. ${ }^{4}$

The presence of elements such as magnesium has a positive effect on the behaviour of the biomaterials, i.e. Dolci et al. ${ }^{5}$ claimed use of hydroxyapatite powder containing $c a .25 \mathrm{wt} \%$ of $\mathrm{Mg}$ for the production of preparations for odontostomatologic applications. However, major drawbacks in the use of synthetic calcium phosphates are their price and use of non-renewable resources. Previous work by the authors has demonstrated that materials prepared with residues from beer production are cytocompatible probably since they contain $\mathrm{P}, \mathrm{Si}, \mathrm{Ca}$ and $\mathrm{Mg}$ as main components, which are also cations present in bone that can act as a scaffold for osteoblast growth. Furthermore, due to its origin these materials are very competitive in price. ${ }^{6-8}$ Moreover, whereas commercial synthesised materials are sold at a price of approximately $150 €$ per gram, beer bagasse (the residue from beer production) that at present is used as a fertiliser has a price of approximately $40 €$ per ton. Taking into account the high water and organic content of this material even though a ton would only yield about $10 \mathrm{~kg}$, this would still have a market value of close to one million euros.

The present work employs residues from beer production from three different plants, chosen so that a comparison of their suitability and any effects of the differences in their chemical compositions on their cytocompatibility and use for bone growth could be determined. Given their origin these new materials can be designated as bioecomaterials. ${ }^{\mathbf{8} 9}$

\section{Materials and methods}

\subsection{Preparation of biomaterials}

Beer bagasse from Lérida (L), Burgos (B) and Guadalajara (G) received from the Mahou San Miguel group (Spain) were first 
dried at $150{ }^{\circ} \mathrm{C}$ during 4 hours, at a heating rate of $5{ }^{\circ} \mathrm{C} \mathrm{min}^{-1}$, in order to avoid putrefaction, due to the humidity of the beer bagasses (70-85 wt\%). The thermal stabilities of the dried materials were determined by TG-DTA analyses to determine the minimum heat treatment temperature necessary to eliminate the organic matter. A TA Instruments Q500 thermobalance with platinum crucibles was used with an air flow of $90 \mathrm{ml}$ $\min ^{-1}$ at a heating rate of $5^{\circ} \mathrm{C} \mathrm{min}^{-1}$. The data were recorded at 4 second intervals with a specific software (Universal V4.2e TA Instruments) to calculate the weight loss versus heating rate (DTG) using ca. $20 \mathrm{mg}$ of sample.

The samples of bagasse were calcined in a Piroval, electric oven MFE64 at $600,700,850$ or $1000{ }^{\circ} \mathrm{C}$, with a heating rate of $5{ }^{\circ} \mathrm{C} \min ^{-1}$, and maintaining the final temperature during 4 hours, the samples thus produced were designated as BBM46, BBM47, BBM48 and BBM410, respectively. The calcined materials were homogenised and their particle sizes controlled by sieving, since preliminary experiments showed the importance of this parameter in the reproducibility of biological behaviour of the materials. The composition of the calcined materials was analysed by means of inductively coupled plasma atomic emission spectroscopy, using a Perkin-Elmer Optima 3300DV apparatus. X-ray diffraction (XRD) patterns of samples were analysed on a PANalytical X'Pert PRO X-ray diffractometer using $\mathrm{Cu} \mathrm{K} \alpha$ radiation $(45 \mathrm{kV}, 40 \mathrm{~mA})$ and parallel beam optical geometry at $2 \theta=15-85^{\circ}$ with a step size of $0.02^{\circ}$ and a counting time of $10 \mathrm{~s}$ per step. The crystalline phases were identified by reference to JCPDS diffraction file data $4-90^{\circ}, 0.04^{\circ}$ per pass 20 seconds and X'Pert HighScore Plus was used to analyse the results. Transmission Infrared Spectroscopy spectra were obtained using a Bruker iFS 66v/S with 100 scans per sample, embedded in $\mathrm{KBr}$ pellet method to identify the chemical structure, collected in the $4000-250 \mathrm{~cm}^{-1}$ wavenumber range. The surface areas of the materials were determined by nitrogen adsorption-desorption on samples previously outgassed overnight at $300{ }^{\circ} \mathrm{C}$ to a vacuum of $<10^{-4}$ torr on a Micromeritics ASAP 2010 to remove any loosely bound adsorbed species. The specific surface areas were determined from the linear portion of the BET plot in the relative pressure range of 0 to 0.4 . The interparticulate and intraparticulate pore volumes of the heat treated materials were determined by mercury intrusion porosimetry (MIP) with a Fisons Pascal 140/240 on samples previously dried in an oven at $150{ }^{\circ} \mathrm{C}$ overnight to ensure that they were free from humidity. A mercury contact angle of $141^{\circ}$ and surface tension of $484 \mathrm{mN} \mathrm{m}^{-1}$ were assumed in accordance with the IUPAC recommendations. The basicity of the solids was measured by desorption-decomposition of acetic acid in a gas analysis system with quadrupole mass spectrometry, model M3 QMS200 Thermostar coupled to a Stanton STA model 781 simultaneous thermogravimetric/differential thermal analysis equipment. Acetic acid was added to the heat treated BB-derived materials and the excess allowed to evaporate before weighing. Approximately $20 \mathrm{mg}$ of this spiked material was used and the basicity, both strength and amount was related to the detection of mass 44 during the sample heating, this mass being related to the generation of $\mathrm{CO}_{2}$ caused by decomposition of the acetic acid. ${ }^{\mathbf{1 0}}$
The materials were prepared for the biostudies by crushing them into a fine powder and then passed through a $120 \mu \mathrm{m}$ sieve, weighed and demineralised water was added to obtain a final concentration of $10 \mathrm{mg} \mathrm{ml}^{-1}$. The suspension was then autoclaved.

\subsection{Cell cultures}

The cell culture results obtained were compared with a reference material, hydroxyapatite (HA), a synthetic calcium phosphate ceramic that mimics the natural apatite composition of bones and teeth and has been described as a potential material to coat scaffolds for promoting osteoblast differentiation. ${ }^{\mathbf{1 1 , 1 2}}$ Osteoblast-like murine MC3T3-E1 cells were cultured in $\alpha$-MEM (Gibco) supplemented with $10 \%$ foetal bovine serum and $1 \%$ penicillin-streptomycin (basal medium). To induce differentiation, cells were placed in osteogenic media: basal medium supplemented with $10 \mathrm{mM} \beta$-glycerophosphate and $50 \mu \mathrm{g} \mathrm{ml} \mathrm{m}^{-1}$ ascorbic acid. Cells were incubated in a humidified atmosphere at $37{ }^{\circ} \mathrm{C}$ and at $5 \% \mathrm{CO}_{2}$. The results are shown as histograms with error bars of statistical average of four experiments for each biomaterial and experimental condition $(p<0.05 ; n=4)$.

\subsection{Cell adhesion and proliferation}

To evaluate the proliferation rate of MC3T3E1 cells grown in the presence of beer bagasse-derived (BB-derived) materials, cell viability was measured following incubation of the MC3T3E1 cells with materials at various concentrations, ranging from 10 to $200 \mu \mathrm{g} \mathrm{ml}^{-1}$ for 7 days. For the viability assays, cells were seeded into 96-well plates (10 000 cells per well; four replicates for each condition). After 24 hours, the cells were treated with materials at the previously specified concentrations and periods of time. The cultures were then washed twice in phosphatebuffered saline to remove any residual material and the tetrazolium dye, 3-(4,5-dimethilthiazol-2)-2,5-diphenyl-2 $H_{-}$ tetrazolium bromide (MTT, $5 \mathrm{mg} \mathrm{ml}^{-1}$ in phosphate-buffered saline; Sigma), was added to the medium for $1 \mathrm{~h}$. After removal of the medium, the precipitated formazan crystals were dissolved in optical grade dimethyl sulphoxide $(200 \mu \mathrm{l})$. The absorbance of each well was measured spectrophotometrically at $570 \mathrm{~nm}$ using an ELX808 microplate reader (BioTeK).

MC3T3E1 cells were seeded into 96-well plates (10 000 cells per well; four replicates for each condition) and grown on basal and osteogenic medium for 15 days in the presence of BBderived materials at the concentrations specified in each experiment. After treatment with the BB-derived materials, the cells were rinsed with PBS and then lysed into PBS containing $0.1 \%$ Triton X-100. Cell lysates were centrifuged and the soluble fraction was used for enzyme assay. Samples were incubated with an assay mixture of $p$-nitrophenyl phosphate ( $p$-NPP) (Sigma). Cleavage of $p$-NPP in a soluble yellow end product, $p$-nitrophenol, which absorb at $405 \mathrm{~nm}$, was used to assess ALP activity. The optical density of $p$-nitrophenol at $405 \mathrm{~nm}$ was determined spectrophotometrically and ALP activities were normalised to total protein content using the bicin-choninic acid (BCA) method. ALP activity was calculated as nanomoles of $p$-nitrophenol liberated per microgram of total cellular protein 
per hour and expressed as percentage of control cells (cells grown in basal medium on polystyrene plates).

\subsection{Cytotoxicity}

The lactate dehydrogenase (LDH) activity was used as an index of the cytotoxicity in the culture media. Cells were plated at a density of 10000 cells per well in 96-well plates on basal and osteogenic medium. Beer bagasse materials were added at the indicated concentrations. After $24 \mathrm{~h}$, the culture media were collected and centrifuged and the supernatant was used for the LDH activity assay. The LDH activity was determined spectrophotometrically using the Cytotoxicity Detection kit (Roche), according to the manufacturer's instructions. The experiments were repeated four times for each of the materials and conditions tested and the results are shown as histograms with error bars of statistical average of the experiments for each biomaterial $(p<0.05 ; n=4)$.

\subsection{Cell differentiation}

Collagen secretion by MC3T3E1 cells cultured in the presence of BB-derived materials was quantified by Sirius Red staining. After culturing MC3T3E1 cells in the presence of the indicated concentrations of BB-derived materials for 15 days, the cells were washed three times with PBS and then fixed in $4 \%$ paraformaldehyde. Following three rinses in PBS, the cell cultures were stained for collagen secretion in a $0.1 \%$ solution of Sirius Red (Sigma) in saturated picric acid for $18 \mathrm{~h}$. After washing with $0.1 \mathrm{M}$ acetic acid until the red colour disappeared, the stain on specimens was eluted in destain solution (0.2 $\mathrm{M} \mathrm{NaOH}-$ methanol $1: 1)$. The optical density at $540 \mathrm{~nm}$ was then measured using a spectrophotometer.

Matrix mineralisation by MC3T3E1 cells was evaluated by Alizarin Red S staining. After culturing MC3T3E1 cells in the presence of the indicated concentrations of BB-derived materials for 15 days, the cells were washed three times with PBS and then fixed in $75 \%$ ethanol for $1 \mathrm{~h}$. The cell cultures were stained with $40 \mathrm{mM}$ Alizarin Red $\mathrm{S}$ in distilled water $(\mathrm{pH} \mathrm{4.2)}$ for $10 \mathrm{~min}$ at room temperature. Afterwards, the cell monolayers were washed with distilled water until no more colour appeared. The stain was dissolved in $10 \%$ cetylpyridinium chloride in $10 \mathrm{mM}$ sodium phosphate ( $\mathrm{pH} 7.0)$ and the absorbance values were measured at $620 \mathrm{~nm}$. The results are shown as the mean \pm standard error of the mean of data from four experiments. The data were analysed by single factor analysis of variance followed by the post hoc Tukey's honestly significant difference test. A significance level of $P<0.05$ was chosen, and Statistica 7.0 (StatSoft Inc, Tulsa, OK) software was used for all statistical tests.

\section{Results}

\subsection{Characteristics of beer bagasse derived biomaterials}

Results from TG-DTA shown in Fig. 1a indicated that the thermal behaviour of the three samples under air treatment was practically identical, with total weight losses found of $c a .97 \%$ of the initial mass, $8 \%$ due to loss of volatile matter and water at

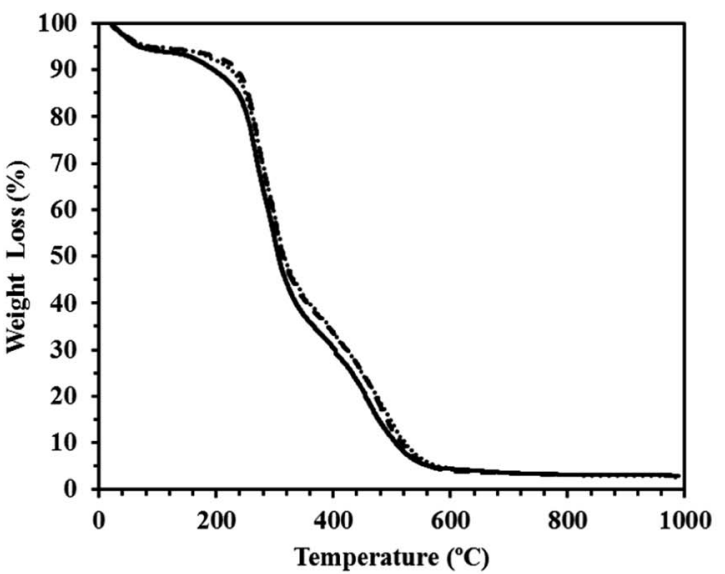

(a)

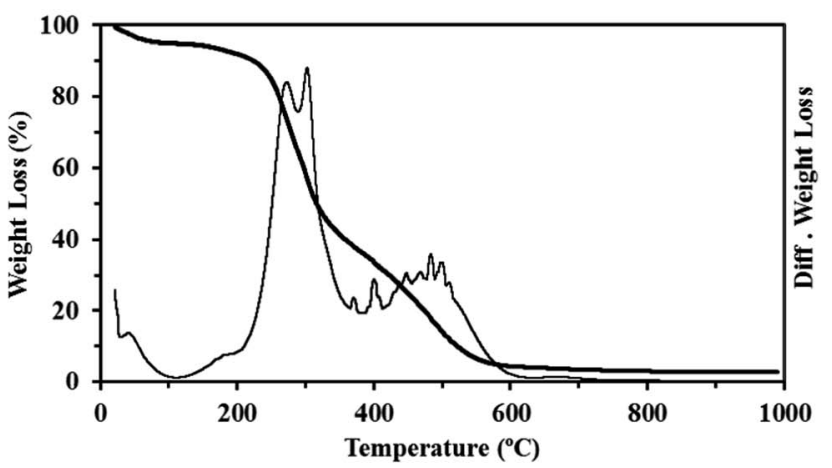

(b)

Fig. 1 (a) Comparison of TG traces for dried beer bagasse from three sources (Lérida ..., Guadalajara -.-., Burgos -). (b) TGA analysis of dried BBM-L ( $-\%$ weight loss, - differential weight loss).

$T<200{ }^{\circ} \mathrm{C}, 55 \%$ loss at $T=200-380{ }^{\circ} \mathrm{C}$ due to decomposition of organic matter (mainly cellulose and hemicellulose) and 34\% lost for $T=380-600{ }^{\circ} \mathrm{C}$, due to lignin decomposition. ${ }^{13,14}$ The result obtained for sample BBM-L (Fig. 1a) was chosen for a more detailed explanation.

The compositions of the heat treated materials for the principle elements are collated in Table 1 , where it may be seen that the variations were: $15-20 \%$ silicon, $12-14 \%$ phosphorous, $7-8 \%$ calcium and $5-7 \%$ magnesium and on increasing the

Table 1 ICP weight percent compositions of biomaterials

\begin{tabular}{lrrrrrrr}
\hline & Ca & Fe & P & \multicolumn{1}{l}{$\mathrm{S}$} & $\mathrm{Si}$ & $\mathrm{Mg}$ & $\mathrm{Na}$ \\
\hline BBM46-L & 6.8 & 0.2 & 13.0 & 0.4 & 14.9 & 6.6 & 0.3 \\
BBM47-L & 7.2 & 0.2 & 13.5 & 0.4 & 15.6 & 6.9 & 0.3 \\
BBM48-L & 7.4 & 0.1 & 13.9 & 0.4 & 16.7 & 7.2 & 0.3 \\
BBM410-L & 7.5 & 0.2 & 13.6 & 0.5 & 17.7 & 7.2 & 0.3 \\
BBM47-B & 7.6 & 0.2 & 13.3 & 0.3 & 17.6 & 5.7 & 0.0 \\
BBM48-B & 8.0 & 0.2 & 13.4 & 0.3 & 17.8 & 5.8 & 0.0 \\
BBM410-B & 8.1 & 0.2 & 12.6 & 0.3 & 19.2 & 5.8 & 0.0 \\
BBM46-G & 7.7 & 0.3 & 12.1 & 0.5 & 15.7 & 4.9 & 0.1 \\
BBM47-G & 8.3 & 0.4 & 12.9 & 0.3 & 18.5 & 5.2 & 0.1 \\
BBM48-G & 8.3 & 0.4 & 12.8 & 0.3 & 19.8 & 5.4 & 0.1 \\
BBM410-G & 8.8 & 0.4 & 12.9 & 0.2 & 19.8 & 5.4 & 0.1 \\
HAP (***) & 36.8 & 0.0 & 13.9 & 0.1 & 0.3 & 0.0 & 0.0
\end{tabular}


heat-treatment temperature the amounts of these major elements increased, due to the loss of volatile species, in agreement with TG-DTA and FTIR data. From the data in Table 1 it may be observed that there were differences in the chemical compositions of the four main elements depending on the source of the beer bagasse but the variations between different batches of beer bagasse from the same source were negligible and within experimental error.

The XRD patterns of the heat treated materials presented in Fig. 2 showed that on increasing the heat-treatment temperature the XRD peaks were better defined and narrower corresponding to the increased crystallinity of the materials on sintering. The main crystalline phases were calcium-magnesium phosphate $\left({ }^{*}\right) 31.5^{\circ}(100 \%), 29.7^{\circ}(85 \%)$ and $29.3^{\circ}(75 \%)$ present at all temperatures ${ }^{15}$ and cristobalite found at temperatures higher than $600{ }^{\circ} \mathrm{C}(+) 21.9^{\circ}\left(100 \%\right.$, (111)), $36^{\circ}(12 \%$, (220)), $31.3^{\circ}(10 \%,(102))$ and $28.4^{\circ}(8 \%,(111)){ }^{16}$ Table 2 includes the crystallite sizes of cristobalite and calcium-
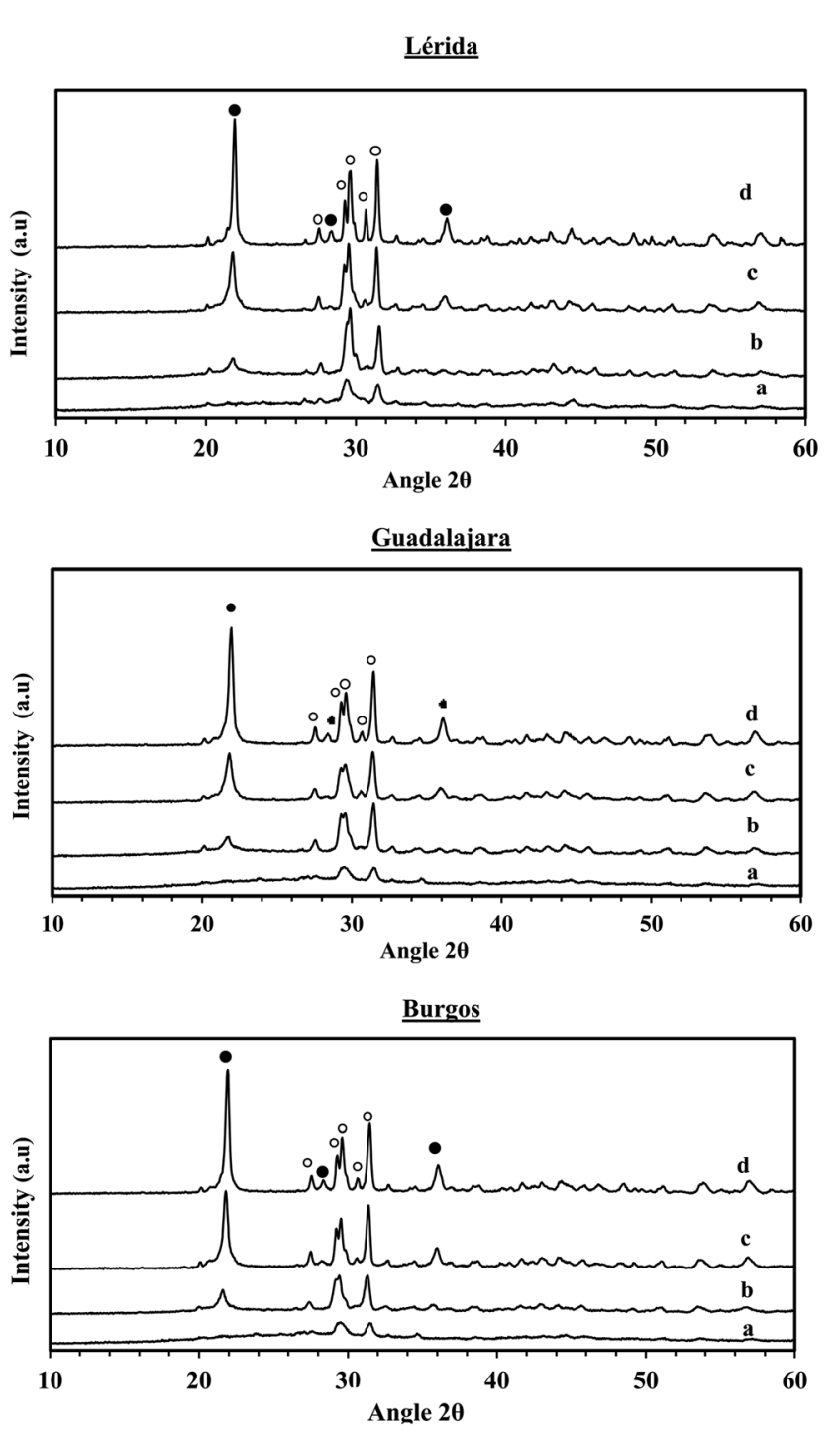

Fig. 2 XRD patterns of materials treated for 4 hours in air at: (a) $600{ }^{\circ} \mathrm{C}$, (b) $700{ }^{\circ} \mathrm{C}$, (c) $850{ }^{\circ} \mathrm{C}$ and (d) $1000^{\circ} \mathrm{C}$. Cristobalite and $\mathrm{O}$ $\mathrm{Ca}-\mathrm{Mg}$ phosphate.
Table 2 Average particle sizes of materials by XRD (Debye-Scherrer) .(a) Silica (experimental width $0.1952 \theta=21.9$ mean peak 4.04). (b) Phosphate (experimental width $0.1622 \theta=31.5$ mean peak 2.83-2.84)

a

\begin{tabular}{llc}
\hline & $\mathrm{FWHM}^{a}{ }^{\circ}$ & $\mathrm{d} \mathrm{nm}^{-1}$ \\
\hline BBM46-L & - & \\
BBM47-L & 0.31 & 70 \\
BBM48-L & 0.29 & 85 \\
BBM410-L & 0.23 & 231 \\
BBM46-B & - & \\
BBM47-B & 0.34 & 56 \\
BBM48-B & 0.29 & 85 \\
BBM410-B & 0.23 & 231 \\
BBM46-G & - & \\
BBM47-G & 0.33 & 60 \\
BBM48-G & 0.33 & 60 \\
BBM410-G & 0.29 & 235 \\
\hline
\end{tabular}

b

\begin{tabular}{llr}
\hline & FWHM/ & \\
\hline BBM46-L & 0.43 & $\mathrm{~d} \mathrm{n}^{-1}$ \\
BBM47-L & 0.23 & 82 \\
BBM48-L & 0.20 & 121 \\
BBM410-L & 0.16 & 250 \\
BBM46-B & 0.45 & $>300$ \\
BBM47-B & 0.23 & 84 \\
BBM48-B & 0.20 & 127 \\
BBM410-B & 0.17 & 217 \\
BBM46-G & 0.48 & $>300$ \\
BBM47-G & 0.22 & 65 \\
BBM48-G & 0.20 & 135 \\
BBM410-G & 0.17 & 201 \\
HAP (***) & 0.17 & $>300$ \\
${ }^{a}$ Full width half maximum. & & $>300$ \\
\end{tabular}

magnesium phosphate phases as calculated following the Debye-Scherrer approach. No crystalline cristobalite was found for BBM46 but values of 56 to $70 \mathrm{~nm}, 60$ to $85 \mathrm{~nm}$ and 85 to $230 \mathrm{~nm}$ were found for BBM47, BBM48 and BBM410, respectively (Table 2a). The peaks corresponding to phosphate indicate mean crystallite sizes of 65 to $84 \mathrm{~nm}$ for BBM46, 121 to $135 \mathrm{~nm}$ for BBM47, 201 to $250 \mathrm{~nm}$ for BBM48 and full crystallisation of phosphate for the BBM410 in all materials.

The three beer bagasses as received showed identical FTIR traces (Fig. 3a) and the heat treated materials prepared from them also displayed identical results, being the one from Lérida (BBM-L) chosen as example (Fig. 3b). For the dried bagasse (Fig. 3a) the main features were a broad band of $\mathrm{O}-\mathrm{H}$ stretching in the $3100-3600 \mathrm{~cm}^{-1}$ region, at $2926 \mathrm{~cm}^{-1}$ the $\mathrm{C}-\mathrm{H}$ aliphatic axial deformation in $\mathrm{CH}_{2}$ and $\mathrm{CH}_{3}$ groups from cellulose, lignin and hemicellulose, at $2854 \mathrm{~cm}^{-1}$ the vibration of $-\mathrm{OCH}_{3}$, present in lignin or hemicelluloses ${ }^{17}$ the band at $1743 \mathrm{~cm}^{-1}$ was the $\mathrm{C}=\mathrm{O}$ stretching of the acetyl groups present in cellulosic material, the bands at 1160 and 1043, corresponded to $\mathrm{O}-\mathrm{H}$ stretching of secondary and primary alcohols, respectively and the band at $1378 \mathrm{~cm}^{-1}$ corresponded to $\mathrm{O}-\mathrm{H}$ vibration of 


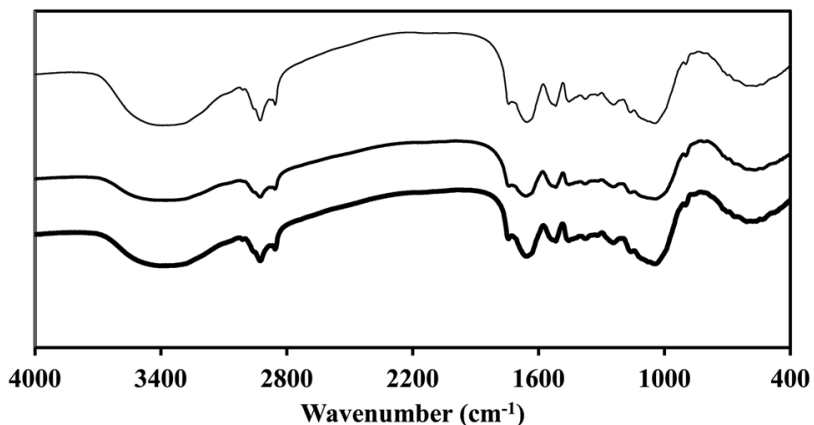

(a)

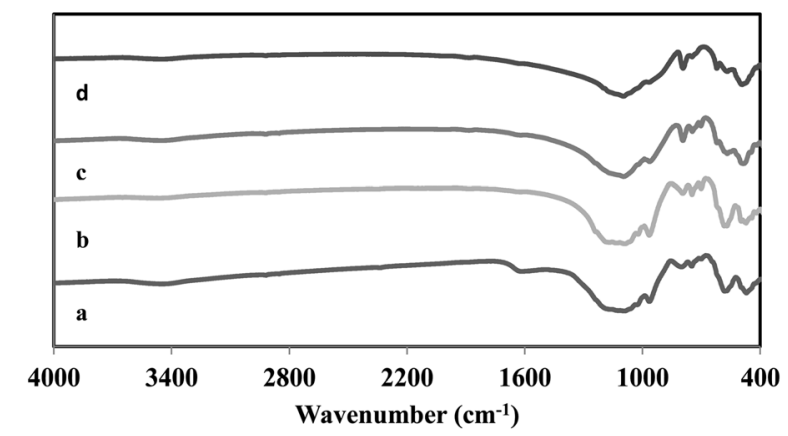

(b)

Fig. 3 (a) FTIR traces of beer bagasses dried at $150{ }^{\circ} \mathrm{C}$ for 4 hours in air from three different sources - Lérida, - Guadalajara and - Burgos. (b) FTIR traces of biomaterials derived from Lérida treated for 4 hours at (a) $600{ }^{\circ} \mathrm{C}$, (b) $700{ }^{\circ} \mathrm{C}$, (c) $850^{\circ} \mathrm{C}$ and (d) $1000^{\circ} \mathrm{C}$.

phenolic groups. The signal at $899 \mathrm{~cm}^{-1}$ could be assigned to $\beta$ glycosidic linkages between monosaccharide units. ${ }^{18}$ The heat treated materials (Fig. $3 \mathrm{~b}$ ) had a broad band at $3466 \mathrm{~cm}^{-1}$ due to the stretching vibration of the $\mathrm{P}-\mathrm{OH}$ and $\mathrm{Si}-\mathrm{OH}$ groups that was diminished with respect to the dried materials (Fig. 3a) due to the loss of these groups on heating. The bands at 1164, 1121 and $1097 \mathrm{~cm}^{-1}$ were due to the $\mathrm{Si}-\mathrm{O}-\mathrm{Si}$ asymmetric stretching vibration. The band at $470 \mathrm{~cm}^{-1}$ was associated with a network $\mathrm{O}-\mathrm{Si}-\mathrm{O}$ bond bending modes. The band at $1023 \mathrm{~cm}^{-1}$ was attributed to the symmetric terminal $\mathrm{P}-\mathrm{O}$ stretching mode of the calcium magnesium phosphate. The band for asymmetric bridge $\mathrm{P}-\mathrm{O}$ stretching mode appeared at $964 \mathrm{~cm}^{-1}$ and those at 579 and 496 were due to the asymmetric bending vibrations of terminal $\mathrm{P}-\mathrm{O}$ bands. ${ }^{19}$

The analyses of porosities and particle size distributions of the heat treated materials are collated in Table 3. Typical MIP curves for these heat treated materials from Burgos are shown in Fig. 4, where it can be seen that the majority of the cumulative intrusion curve was due to the interparticulate void filling and only the materials treated at the lowest temperature had any sign of a slight mesoporosity, i.e. pores of diameter lower than $50 \mathrm{~nm}$, due to intraparticulate porosity, which disappeared on heating at higher temperatures due to sintering of the materials. With increasing heat treatment temperature there was a densification of the sample and a reduction in the overall cumulative pore volume with a slight displacement of the curves to wider pores. Since the cumulative intrusion curve represents the void filling between the aggregates of the primary particles an evaluation of their size may be made using the Mayer-Stowe theory ${ }^{20}$ that relates the porosity of the sample to a packing factor used to estimate the particle size from the width of the spaces between the particles, assuming spherical particle geometry. From the results it may be seen that with increased heat treatment temperature there was larger aggregate sizes and a densification of the materials due to sintering of the samples, in accordance with the results observed from the XRD analyses of these materials. ${ }^{21}$

The adsorption of acetic acid used to characterise the basic sites produces mainly carbonate, bidentate or bridged acetate species, that decompose to $\mathrm{CO}_{2}$, giving rise to bands due to the interaction with basic centres of higher basicity with increasing temperature, i.e. $T<150{ }^{\circ} \mathrm{C}$ for the desorption of physically adsorbed $\mathrm{CO}_{2}$, those at $T=400{ }^{\circ} \mathrm{C}$ corresponding to molecules of $\mathrm{CO}_{2}$ evolved from basic sites of low to medium strength, whilst those at $T=620{ }^{\circ} \mathrm{C}$ corresponded to the interaction with basic sites of high strength (Fig. 5). As can be seen, BB-derived biomaterials prepared with higher heat treatment temperature present lower amount of basic sites, in agreement with the sintering behaviour described confirmed by the increased crystallinity and density and reduction in specific surface area shown by the other characterization techniques.

\subsection{Cell adhesion and proliferation}

Cell proliferation assays were performed in order to determine the influence of the origin of the bagasses and the effect of the temperature to which they were subjected in the presence of increasing concentrations of BB-derived materials from Lérida, Guadalajara and Burgos treated at increasing temperatures, after culturing cells in basal medium for 7 days. The results are shown as histograms with error bars of statistical average of four experiments for each biomaterial $(p<0.05 ; n=4)$. No statistically significant differences between groups with respect to each control were found (Fig. 5).

Results showed a decrease in proliferation of MC3T3E1 cells growing in the presence of hydroxyapatite and materials obtained from beer bagasse, compared to control cells grown on polystyrene plates. The differences among beer bagasses from different sources were not statistically significant. When beer bagasses were treated at higher temperatures an increase in cell proliferation rates was observed. According to these findings, further cytotoxicity assays and cell differentiation experiments were performed on the BB-derived biomaterials treated at $1000{ }^{\circ} \mathrm{C}$.

\subsection{Cytotoxicity assay}

Cytotoxicity, indicated by the lactate dehydrogenase (LDH) activity in the culture media after $24 \mathrm{~h}$ of incubation, was analysed in MC3T3E1 cells cultured in the presence of BB-derived materials treated at $1000{ }^{\circ} \mathrm{C}$ for $4 \mathrm{~h}$ obtained from different sources (Fig. 6). Cells cultured in the presence of BB-derived materials at low (Fig. 6a) or high (Fig. 6b) concentration, showed no obvious cytotoxicity compared to cells grown in the 
Table 3 Textural Characterisation results

\begin{tabular}{|c|c|c|c|c|c|c|}
\hline Material & $\begin{array}{l}\text { Heat treatment } \\
\text { temperature }{ }^{\circ} \mathrm{C}\end{array}$ & $\begin{array}{l}\text { Surface area } \\
\left(S_{\mathrm{BET}}\right) \mathrm{m}^{2} \mathrm{~g}^{-1}\end{array}$ & $\begin{array}{l}\text { Interparticulate } \\
\text { pore volume } \mathrm{cm}^{3} \mathrm{~g}^{-1}\end{array}$ & $\begin{array}{l}\text { Porosity } \\
\%\end{array}$ & $\begin{array}{l}\text { Skeletal } \\
\text { density } \mathrm{g} \mathrm{cm}^{-3}\end{array}$ & $\begin{array}{l}\text { Aggregate } \\
\text { size } \mu \mathrm{m}\end{array}$ \\
\hline \multirow[t]{3}{*}{ BBM-B } & 700 & 3.3 & 3.92 & 90.6 & 2.20 & 148 \\
\hline & 1000 & 0.5 & 2.17 & 86.7 & 3.49 & 194 \\
\hline & 700 & 4.2 & 3.52 & 90.5 & 2.50 & 148 \\
\hline BBM-G & 850 & 0.9 & 3.46 & 89.8 & 2.76 & 191 \\
\hline \multirow[t]{2}{*}{ BBM-L } & 850 & 0.9 & 2.95 & 88.2 & 2.79 & 191 \\
\hline & 1000 & 0.4 & 2.49 & 87.7 & 3.21 & 191 \\
\hline
\end{tabular}

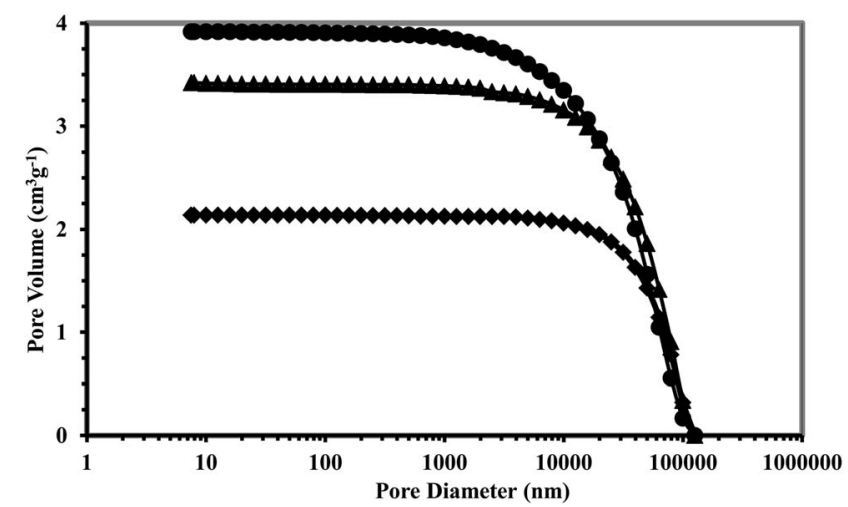

Fig. 4 Mercury intrusion porosimetry results for beer bagasse from Burgos treated for 4 hours at $700^{\circ} \mathrm{C}, \Delta 850^{\circ} \mathrm{C}$ and $\bullet 1000^{\circ} \mathrm{C}$.

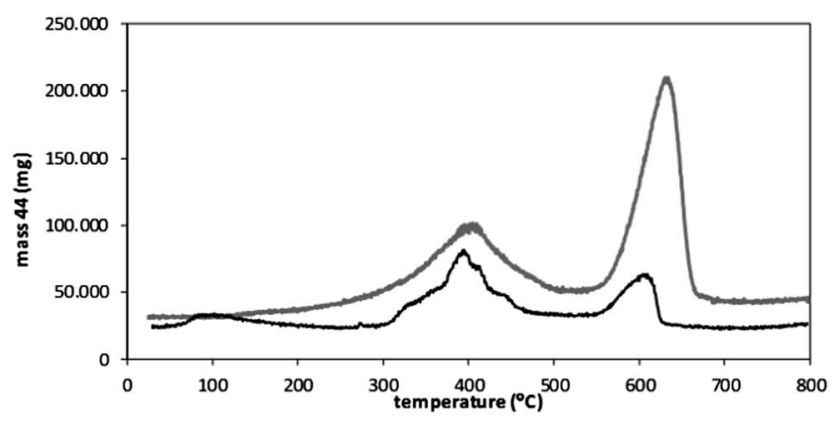

Fig. 5 TG-MS analyses of the amount and strength of basic sites by evolution of mass 44 due to acetic acid decomposition. Grey line: BBM410. Black line: BBM46.

presence of hydroxyapatite and polystyrene culture plates, used as controls. The results are shown as histograms with error bars of statistical average of four experiments for each material $(p<0.05 ; n=4)$.

\subsection{Cell differentiation}

The capacity of cells growing in the presence of BB-derived materials was also evaluated to express alkaline phosphatase, an early marker of osteoblastic cell differentiation. Osteoblastic differentiation after 15 days was assessed by alkaline phosphatase (ALP) activity, when MC3T3E1 cells were cultured with low (Fig. 7a) and high (Fig. 7b) concentrations of BB-derived materials in both, basal and osteogenic media. ALP activity of each condition was quantified and compared to that present in cells grown on polystyrene plates (control).

ALP activity was higher in cells grown in osteogenic medium than in cells cultured in basal medium, as we would predict. However, no difference in ALP activity was observed in MC3T3E1 cells grown in the presence of either, high or low concentrations of BB-derived materials compared with their corresponding control cells. These results established that the presence of BB-derived materials at low and high concentrations did not affect ALP activity.

The production of collagen, the main extracellular matrix protein expressed in bone, was also evaluated. Collagen production quantified by Sirius Red staining was measured in MC3T3E1 cells after 15 days of culture in both basal and osteogenic media (Fig. 8). Cells were cultured in the presence of BBderived materials at low $\left(10 \mu \mathrm{g} \mathrm{ml}{ }^{-1}\right)$ and high $\left(100 \mu \mathrm{g} \mathrm{ml}{ }^{-1}\right)$ concentrations. According to the quantitative results shown in Fig. 8, collagen deposition was promoted when MC3T3E1 cells were grown in osteogenic medium in all conditions, as expected and no significant difference in collagen production was observed when cells were grown in the presence of BB-derived materials compared with cells grown on plastic plates, neither in basal nor osteogenic medium.

Besides its effect on ALP activity and collagen synthesis, we determined whether BB-derived materials might affect the mineralisation of the matrix formed by MC3T3-E1 cells. The presence of calcium in cellular deposits can be confirmed by Alizarin Red S staining. Extracellular matrix mineralisation measured by Alizarin Red S staining is shown in Fig. 9. Cells grown in osteogenic medium for 15 days displayed the highest calcium content, an indicator of mineralisation nodule formation, in all conditions tested. However, treatment with BBderived materials for 15 days at concentrations of 10 and $100 \mu \mathrm{g}$ $\mathrm{ml}^{-1}$ (Fig. 9a and b, respectively), did not significantly affect the mineralisation rates compared with control cells grown on polystyrene plates. In this case, HA (a material which contains $\mathrm{Ca} / \mathrm{P}$-apatite) could not be used as a control due to the high background produced by the material itself. These results indicated that BB-derived materials did not affect the normal mineralisation induced by MC3T3-E1 cells in long-term cultures. 


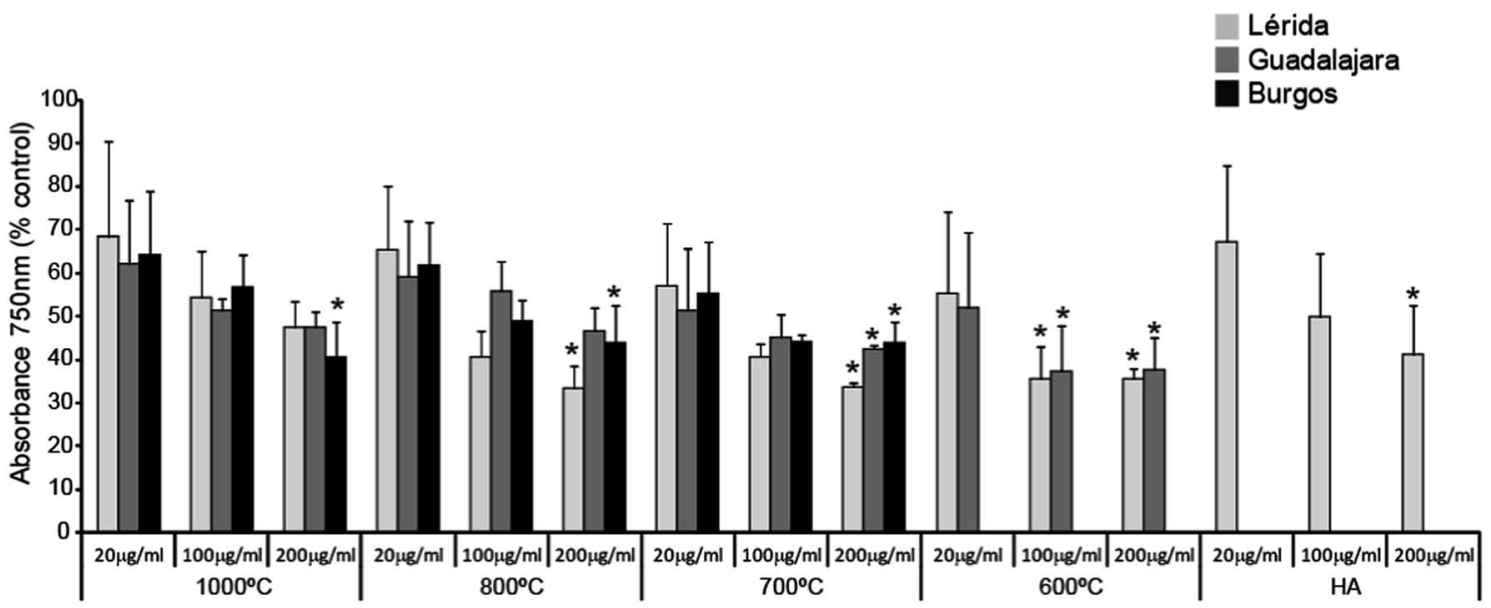

Fig. 6 MC3T3-E1 proliferation analysis by MTT assay on cells treated with different concentrations of BB-derived materials treated at several temperatures after one week in culture.
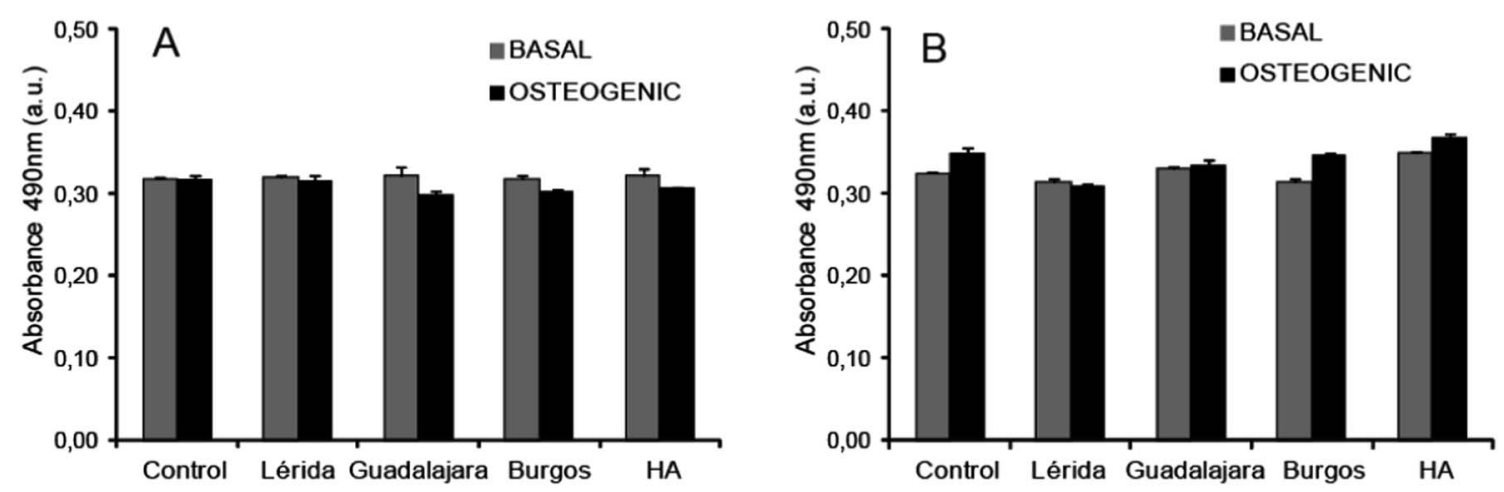

Fig. 7 Cytotoxicity study by lactate dehydrogenase (LDH) activity assay on MC3T3-E1 cells treated with $10 \mu \mathrm{g} \mathrm{ml} \mathrm{l}^{-1}(\mathrm{~A})$ and $100 \mu \mathrm{g} \mathrm{ml} \mathrm{l}^{-1}$ (B) of BB-derived materials treated at $1000^{\circ} \mathrm{C}$ after $24 \mathrm{~h}$ in culture.

A

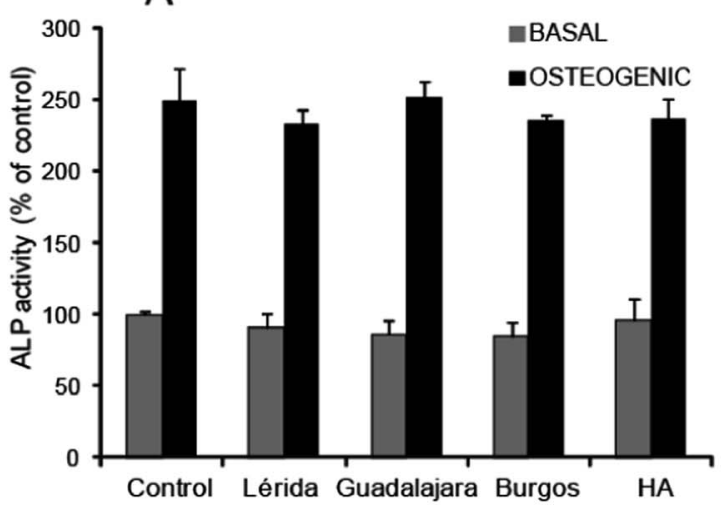

B

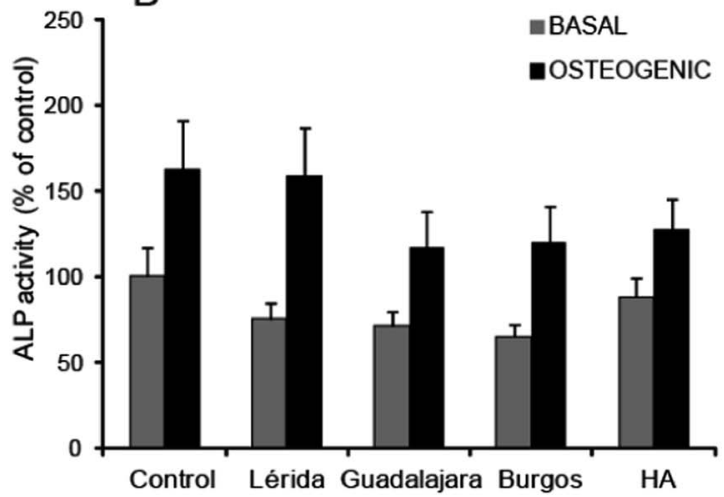

Fig. 8 MC3T3-E1 differentiation study by alkaline phosphatase (ALP) activity assay on cells treated with $10 \mu \mathrm{g} \mathrm{ml} \mathrm{l}^{-1}$ (A) and $100 \mu \mathrm{g} \mathrm{ml} \mathrm{l}^{-1}$ (B) of BB-derived materials after two weeks culture.

\section{Discussion}

Biomaterials based on composites of calcium phosphates and silica have the ability to bond directly to bone and thus enhance bone formation through supply of chemicals needed to support cell function and tissue formation (bioactivity), and resorbability, depending mainly on their chemical composition and crystalline structure. On the one hand, hydroxyapatite has a high chemical stability and low bioactivity, while calcium deficient hydroxyapatite has higher bioactivity and solubility, and 

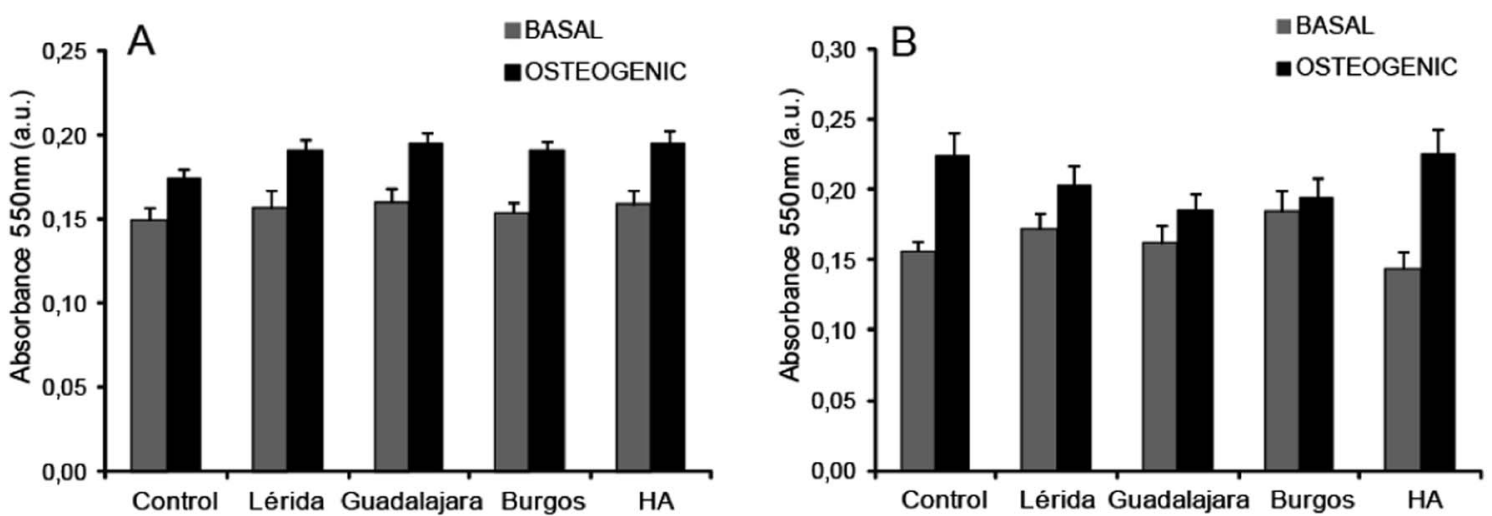

Fig. 9 MC3T3-E1 differentiation study by collagen production (Sirius Red staining) on cells treated with $10 \mu \mathrm{g} \mathrm{ml} \mathrm{l}^{-1}(\mathrm{~A})$ and $100 \mu \mathrm{g} \mathrm{ml} \mathrm{l}^{-1}$ (B) of BB-derived materials after two weeks culture.

on the other hand silicates have high rates of bioactivity and resorbability compared to hydroxyapatite, because their surfaces transform into a bioactive hydroxyapatite layer when contacted with physiological solution due to its nucleation on the $\mathrm{Si}-\mathrm{OH}$ moieties. As a consequence silica (cristobalite)calcium phosphate composites can be tailored to have enhanced bioactivity and resorbability and therefore osteoinductivity, related to material composition and porosity. ${ }^{22-26}$ Addition of $\mathrm{SiO}_{2}$ to the calcium phosphate scaffolds increases mechanical strength, cellular proliferation and the dissolution/ resorption rates. ${ }^{27,28}$

The presence of magnesium in the biomaterials favours bone growth, promotes osteogenic differentiation of preosteoblasts and improves implant osseointegration during the early stages of bone healing. As the scaffolds degrade in vivo, their elements are released and they promote cell proliferation and differentiation..$^{29-31}$

The materials prepared here are biphasic phosphates of calcium and magnesium and silica, both amorphous and in the form of cristobalite, since its crystallinity increases with higher heat treatment temperatures (Table 2) and their porosities all lie within the 10 to $100 \mu \mathrm{m}$ range, all of these characteristics making them suitable to promote cell proliferation and differentiation as demonstrated in the evaluation of different parameters to assess the cytocompatibility of the BB-derived materials in an osteoblastic cell line, MC3T3E1.

The MC3T3-E1 osteogenic cells are a widely used model to study in vitro matrix mineralisation. These cells are able to differentiate into osteoblasts that express strong ALP activity and to form a collagenous matrix organised in 3-dimensional nodules, which progressively become mineralised in the presence of ascorbic acid and phosphate. ${ }^{32}$ In this system, MC3T3E1 cells display a time-dependent and sequential expression of osteoblast characteristics analogous to in vivo bone formation..$^{33}$

From a biological perspective, it has been shown that some biomaterials are able to modify directly the osteoblastic proliferation rate and its differentiation, such as the synthesis of alkaline phosphatase, matrix mineralisation and collagen secretion. ${ }^{34,35}$ Therefore, in vitro proliferation and differentiation responses of osteoblast-like cells (MC3T3-E1 cell line) to the BB-derived powders were studied. Various biological responses to the biomaterials were assayed, including cell viability determinations by the MTT and LDH assays, evaluation of ALP activity in, evaluation of matrix mineralisation and TypeI collagen secretion at the differentiation period.

We have found that the addition of BB-derived materials to MC3T3E1 cells did not considerably alter the cytocompatibility and osteogenicity of the cells. When BB-derived materials were subjected to $1000{ }^{\circ} \mathrm{C}$ for $4 \mathrm{~h}$, proliferation analysis assessed by MTT test showed a significant cell growth. However, a decrease in cell proliferation rates was observed when BB-derived materials were subjected at low temperatures $\left(600{ }^{\circ} \mathrm{C}\right)$. An initial delay of cell proliferation was also detected in MC3T3E1 cells growing in the presence of ionic doped carbonated hydroxyapatite/ $\beta$-tricalcium phosphate powders. ${ }^{36}$ The initial lower metabolic levels of cells exposed to the powders appear to correlate with their specific characteristics. The delays of cell proliferation correlate with a more basic $\mathrm{pH}$ for the powdercontaining media at the first day in culture, which may initially result in lower cellular enzymatic efficiency and hence in slower processes (e.g. cell division and metabolism) than control cells. ${ }^{36}$

The different relative metabolic levels at day 7 found in MC3T3E1 cells growing in the presence of BB-derived materials also correlate with specific characteristics of the powders, where the materials treated at lower temperatures produced a higher increase in the $\mathrm{pH}$ of the culture medium due to their greater basicities (shown in Fig. 5) and a lower proliferation rate of MC3T3E1 cells.

Results obtained in LDH assay when MC3T3-E1 cells were cultured in the presence of low and high concentrations of BBderived materials for $24 \mathrm{~h}$ support the cytocompatibility of the new materials synthesised.

The effects of direct contact of BB-derived materials and osteoblast-like cells in terms of cell differentiation were evaluated by testing ALP activity, collagen production and extracellular matrix mineralisation after 15 days. In the case of MC3T3E1 cells, previous studies have demonstrated that expression of osteoblastic markers begins after culturing the cells with medium supplemented with $\beta$-glycerol-phosphate 

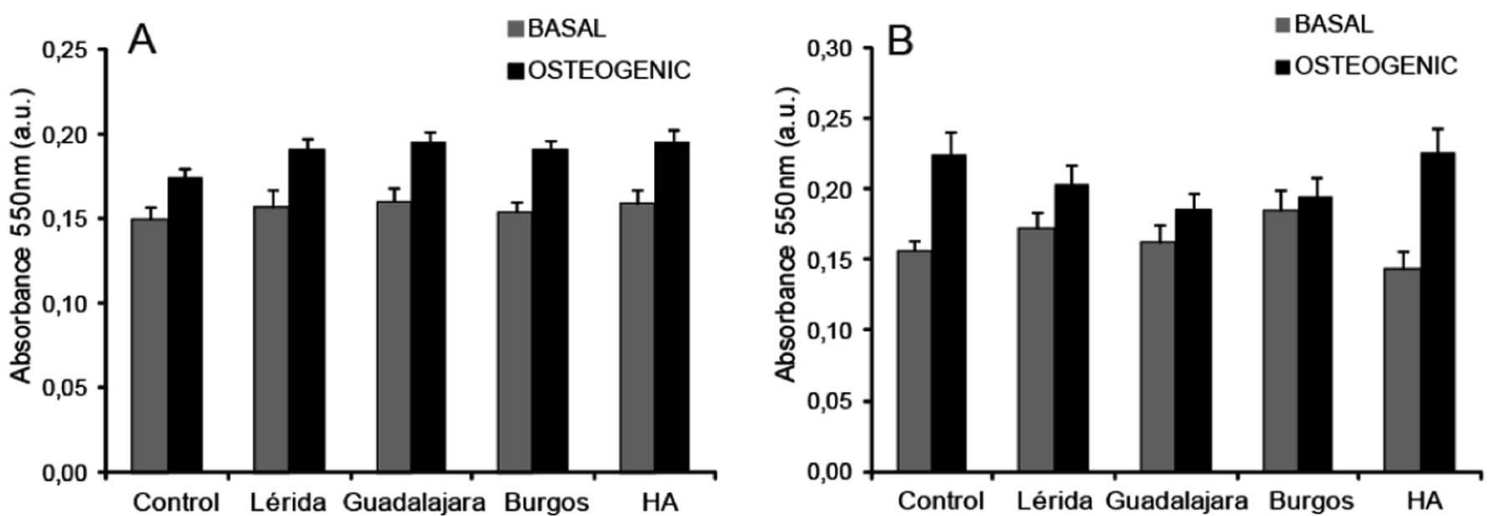

Fig. 10 MC3T3-E1 differentiation study by extracellular matrix mineralisation (Alizarin Red S staining) on cells treated with $10 \mu \mathrm{g} \mathrm{ml} \mathrm{l}^{-1}$ (A) and 100 $\mu \mathrm{gl}^{-1}(\mathrm{~B})$ of BB-derived materials after two weeks culture.

and ascorbic acid. ${ }^{33}$ Under these culture conditions, alkaline phosphatase activity (ALP) begins to be expressed after 1 week and reaches a maximum after 2 weeks. The behaviour of osteoblast-like cells (MC3T3-E1) co-cultured with the BB-derived materials were not affected by the test conditions, the MC3T3E1 cells treated with BB-derived materials showing ALP activity profiles similar to the control. Results indicated that MC3T3-E1 cells maintain their capability to express active ALP enzymes when growing in the presence of BB-derived powders.

To confirm that osteoblastic cells exposed to the BB-derived materials indeed maintained the ability to differentiate at similar levels to control cells, the profile of Type-I collagen cellular secretion was also analysed. The addition of ascorbic acid in MC3T3-E1 cells is known to induce the deposition of collagen in the extracellular matrix. ${ }^{33} \mathrm{We}$ found that osteogenic medium increased collagen synthesis in MC3T3-E1 cultures compared with basal medium. However, non-exposed and BBderived powder-exposed cells secrete similar collagen amounts into the extracellular medium. In addition to osteoblast proliferation and differentiation, such as ALP activity and collagen synthesis, extracellular matrix mineralisation is also one of the major parts of bone formation. MC3T3-E1 cells are known to deposit minerals in the collagenous matrix in the presence of $\alpha$-glycerol phosphate. ${ }^{37}$

Minerals formed in vitro were found to consist of calcium and phosphorus deposited on well-bonded collagen fibrils, and some of the crystals matured into hydroxyapatite crystals. ${ }^{38}$ We assessed whether the treatment of MC3T3-E1 with BB-derived materials affected matrix mineralisation. Extracellular matrix calcium deposits for mineralised nodule formation were stained with Alizarin red S dye which combines with calcium ions. Alizarin red S staining showed that culturing MC3T3-E1 cells in osteogenic medium increased extracellular matrix calcium accumulation. In the presence of BB-derived materials we found that nodule calcification occurred normally indicating that supplementation with BB-derived materials at the dose used did not affect matrix mineralisation in vitro. It has been described that aluminium inhibited osteoblast mediated mineralisation in MC3T3E1 cultures. ${ }^{39}$ However, the presence of very low doses of aluminium $(<0.1 \%)$ in all the BB-derived materials analysed, was not found to inhibit mineralisation of the extracellular matrix formed by MC3T3-E1 cells (Fig. 10).

In conclusion, the present data show that BB-derived materials affect the proliferation rates of MC3T3E1 cells in a concentration dependent manner at 7 days of incubation. The decrease in cell proliferation rate in the presence of BB-derived materials was similar to that obtained when culturing MC3T3E1 cells with the same concentrations of HA. The osteoblast functions in the presence of BB-derived materials showed normal cell differentiation profiles with respect to alkaline phosphatase activity, collagen secretion and extracellular matrix mineralisation. All these parameters were maintained compared with control cells grown on plastic plates and with those obtained when culturing MC3T3-E1 cells in the presence of the same amounts of HA.

On the whole, the in vitro cell culture experiments suggest that the new BB-derived materials obtained were as osteogenic as HA powder. The results obtained show that the BB-derived materials were cytocompatible, since in vitro observations performed by biochemical test such as LDH assay, support their cytocompatibility. The maintenance of alkaline phosphatase activity, collagen secretion and extracellular matrix mineralisation may lead to bone maturation around the implant without compromising the bone mass and osseointegration. Moreover, the fabrication method reported here is simple, inexpensive, and is easily adoptable by the biomedical industry.

When cultured with osteoblast cells, BB-derived scaffolds were shown to be non-cytotoxic and supported cell growth and differentiation. Together the results suggest that the developed materials may potentially be used to prepare scaffolds for bone tissue engineering applications.

\section{Conclusions}

Residues from the beer industry were used to prepare biomaterials capable to support osteoblast growth. The use of these waste materials gives them an added value as a sustainable, environmentally friendly and economic supply of nanostructured powders for use in osteoporotic treatments. 
The results from this study have shown that the BB-derived materials were as osteogenic, with cytocompatibilities similar to HA powder, commonly used in bone and teeth replacement therapies. Furthermore, the preparation method used in this work was simple, inexpensive and easily adoptable by the biomedical industry. The use of these BB-derived materials as coatings of metallic and ceramic bioimplants for odontoestomatologic treatments, or to form part of 3D scaffolds with pore sizes designed with the desired characteristics for bone replacement, is currently under study.

\section{Acknowledgements}

This work was financially supported by Project RAMBIDENT (INNPACTO 2011, IPT-2011-1935-310000). The authors wish to acknowledge the supply of beer bagasse by the Mahou-San Miguel group, used in this study.

\section{References}

1 Q. Hu, Z. Tan, Y. Liu, J. Tao, Y. Cai, M. Zhang, et al., J. Mater. Chem., 2007, 17, 4690.

2 D. Puppi, N. Detta, A. M. Piras, F. Chiellini, D. A. Clarke, G. C. Reilly, et al., Macromol. Biosci., 2010, 10, 887.

3 E. M. Bueno and J. Glowacki, Nat. Rev. Rheumatol., 2009, 5, 685.

4 Q. Hou, P. A. De Bank and K. M. Shakesheff, J. Mater. Chem., 2004, 14, 1915.

5 G. Dolci, R. Mongiorgi, C. Prati and G. Valdre. Odontostomatologic use of apatite-based nanostructured materials, US Pat., WO 00/03747, 1998.

6 M. Yates, M. A. Martin-Luengo and B. Casal. Preparation of biocompatible materials from beer production and their uses, Spanish Pat., 070475, 2010.

7 M. A. Martin-Luengo, M. Yates, M. Ramos, E. Saez Rojo, A. M. Martinez Serrano and L. Gonzalez Gil, Green Chem. Lett. Rev., 2011, 4, 229.

8 M. A. Martin-Luengo, M. Yates, M. Ramos, F. Plou, J. L. Salgado, J. L. Lacomba, G. Reilly and C. Vervaet, in Sustainable materials and biorefinery chemicals from agriwastes, ed. V. Abrol and P. Sharma, Resource management for sustainable agriculture: Croatia: INTECH, 2012, pp. 49-84.

9 K. Halada, Curr. Opin. Solid State Mater. Sci., 2003, 7, 209.

10 M. A. Martin-Luengo, M. Yates, M. Diaz, E. Saez Rojo and L. Gonzalez Gil, Appl. Catal., B, 2011, 106, 488.

11 Y. H. Koh, C. J. Bae, J. J. Sun, I. K. Jun and H. E. Kim, J. Mater. Sci.: Mater. Med., 2006, 17, 773.

12 R. Budiraharjo, K. G. Neoh and E. T. Kang, J. Colloid Interface Sci., 2012, 366, 224.

13 E. Mészáros, E. Jakab, G. Várhegy, P. Szepesvary and B. Marosvolgyj, J. Anal. Appl. Pyrolysis, 2004, 72, 317.
14 P Parthasarathy, K. S. Narayanan and L. Arockiam, Biomass and Bioenergy, 2013, 58, 58.

15 K. Kieswetter, T. W. Bauer, S. A. Brown, F. Van Lente and K. Merritt, Biomaterials, 1994, 15, 183.

16 J. G. Thompson, A. Melnitchenko, S. R. Palethorpe and R. L. Withers, J. Solid State Chem., 1997, 131, 24.

17 A. A. M. A. Nada, M. El-Sakhawy and S. M. Kamel, Polym. Degrad. Stab., 1998, 60, 247.

18 C. R. Soccol, L. P. D. S. Vandenberghe, A. Bianchi, P. Medeiros, S. G. Karp, M. Buckeridge, et al., Bioresour. Technol., 2010, 101, 4820.

19 A. Butscher, M. Bohner, C. Roth, A. Ernstberger, R. Heuberger, N. Doebelin, et al., Acta Biomater., 2012, 8, 373. 20 R. P. Mayer and R. A. Stowe, J. Colloid Sci., 1965, 20, 893.

21 M. Yates, Part. Part. Syst. Charact., 2006, 23, 94.

22 M. Mastrogiacomo, A. Papadimitropoulos, A. Cedola, F. Peyrin, P. Giannoni, S. G. Pearce, et al., Biomaterials, 2007, 28, 1376.

23 A. Papadimitropoulos, Biotechnol. Bioeng., 2007, 98, 271.

24 G. Mestres, C. Le Van and M. P. Ginebra, Acta Biomater., 2012, 8, 1169.

25 A. El-Ghannam and P. Ducheyne, Bioactive Ceramics. Comprehensive Biomaterials, in Metallic, Ceramic and Polymeric Biomaterials, Charlotte, 2011, pp. 157-179.

26 K. A. Hing, P. A. Revell, N. Smith and T. Buckland, Biomaterials, 2006, 27, 5014.

27 A. Bandyopadhyay, S. Bernard, W. Xue and S. Bose, J. Am. Ceram. Soc., 2006, 89, 2675.

28 A. M. Pietak, J. W. Reid, M. J. Stott and M. Sayer, Biomaterials, 2007, 28, 4023.

29 E. J. Kim, S. Y. Bu, M. K. Sung and M. K. Choi, Biol. Trace Elem. Res., 2013, 152, 105.

30 S. F. Zhao, Q. H. Jiang, S. Peel, X. X. Wang and F. M. He, Clin. Oral Implants Res., 2011, 24, 34.

31 J. Wei, J. Jia, F. Wu, S. Wei, H. Zhou, H. Zhang, et al., Biomaterials, 2010, 31, 1260.

32 D. Wang, K. Christensen, K. Chawla, G. Z. Xiao, P. H. Krebsbach and R. H. Franceschi, J. Bone Miner. Res., 1999, 14, 893.

33 L. D. Quarles, D. A. Yohay, L. W. Lever, R. Caton and R. J. Wenstrup, J. Bone Miner. Res., 1992, 7, 683.

34 D. Puleo, K. Preston, J. Shaffer and R. Bizios, Biomaterials, 1993, 14, 111.

35 P. Valerio, M. M. Pereira, A. M. Goes and M. F. Leite, Biomaterials, 2004, 25, 2941.

36 S. Kannan, S. I. Vieira, S. M. Olhero, P. M. Torres, S. Pina, O. A. Cruz Silva, et al., Acta Biomater., 2011, 7, 1835.

37 H. Sudo, H. A. Kodama, Y. Amagai, S. Yamamoto and S. Kasai, J. Cell Biol., 1983, 96, 191.

38 N. Fratzl-Zelman, P. Fratzl, H. Hörandner, B. Grabner, F. Varga, A. Ellinger, et al., Bone, 1998, 23, 511.

39 K. Ikeda, T. Matsumoto, K. Morita, K. Kurokawa and E. Ogata, Calcified Tissue Int, 1986, 39, 319. 